\title{
Conceptual vocabulary in Grade 2 isiZulu-English and Grade 1 Afrikaans-English bilinguals
}

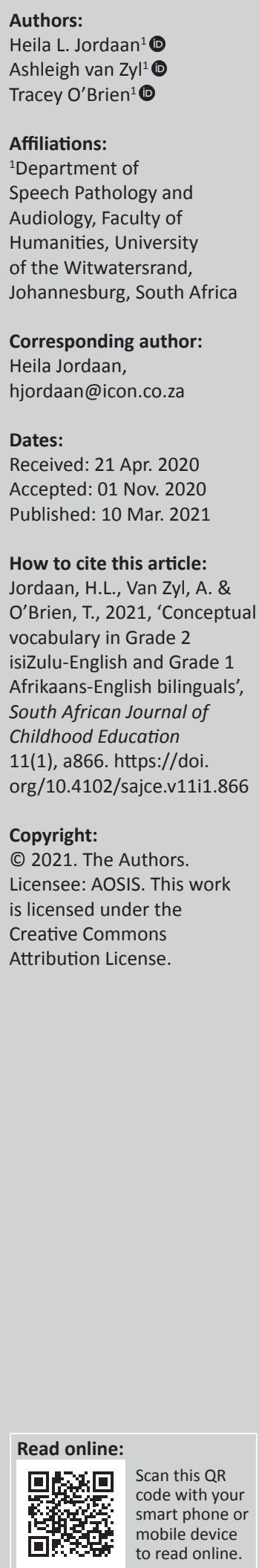

Background: The educational context in South Africa does not always support the development of bilingualism to enable the cognitive and social advantages of dual language proficiency. The emphasis on English as the language of instruction overlooks bilingual competence. This study attempts to show that by considering conceptual vocabulary, professionals can gain a better understanding of childhood bilingualism.

Aim: The aim of the study was to assess the receptive, expressive and conceptual vocabulary of English-isiZulu and English-Afrikaans bilingual children.

Setting: The study was conducted at two primary schools in Johannesburg, Gauteng, in which the language of teaching and learning is English from Grade 1.

Methods: The study employed a comparative within- and between-group quantitative design. The vocabulary of 30 Grade 1 Afrikaans-English and 30 Grade 2 IsiZulu-English bilinguals and their age-matched monolingual peers was assessed using the English Receptive and Expressive One Word Picture Vocabulary tests and adapted isiZulu and Afrikaans versions of the tests for the bilingual groups.

Results: Both bilingual groups obtained significantly higher scores in English than in their home languages across receptive and expressive modalities. The conceptual scores were significantly higher than scores on single language tests. The isiZulu-English group obtained significantly lower scores than the monolingual group in English, even with conceptual scoring, while the Afrikaans-English bilingual group obtained scores similar to and even higher than those of their monolingual peers using conceptual scoring.

Conclusion: This study confirms the value of considering dual language knowledge in bilingual children and underlines the need to support, develop and maintain all South African languages in education.

Keywords: bilinguals; conceptual vocabulary; isiZulu; Afrikaans; English.

\section{Introduction}

Across the world, bilingualism or multilingualism is an increasingly pervasive phenomenon and professionals working with children confront a number of questions pertaining to educational provision, assessment and support for typically - and atypically - developing children who are exposed to two or more languages (Armon-Lotem \& De Jong 2015). South Africa, with its rich tapestry of languages, provides excellent opportunities to explore the complexity of childhood bilingualism in order to address some of the following questions, specifically related to the vocabulary of dual language children:

- How do the vocabularies in the two languages of bilinguals compare to each other?

- Is the vocabulary of the home language affected when bilinguals are educated in English, their second language?

- What are the best methods to assess the vocabulary of bilinguals?

- How are the vocabulary skills of bilingual children similar to or different from those of monolingual children?

To address these questions, this study investigated the vocabulary of two groups of young bilingual learners who speak isiZulu or Afrikaans as their home languages and attend English-medium schools. 


\section{Vocabulary}

The focus of this study was on vocabulary or word knowledge as a component of language proficiency because it plays a particularly important role in literacy. This is a problematic issue in the South African education context at present, with the majority of Grade 4 learners not being able to read for meaning (Howie et al. 2017). Both decoding and comprehending text depend on vocabulary knowledge (Dickinson \& Porche 2011; Durgunoğlu \& Bigelow 2017; Kim \& Pallante 2012). Vocabulary improves reading comprehension, and children need to understand $98 \%$ of the words they read to derive meaning from text (Seifert 2016). In addition, children who develop a rich vocabulary tend to be deeper thinkers, express themselves better and read more. Vocabulary also supports conceptualisation, understanding word formation processes and the development of 'fast mapping', which is the ability to learn new words from context (Hoff 2006). These processes are relevant as learners progress through school and need to acquire increasingly complex concepts and academic vocabulary in the content subjects.

\section{Vocabulary assessment}

As is the case in the current study, vocabulary knowledge is regularly assessed using specifically designed tests. It is possible to assess both the understanding of words (receptive vocabulary) through the selection of an appropriate illustration from a group of 3-4 pictures and the ability to verbally provide a vocabulary verbally item by naming a picture (expressive vocabulary). These methods of assessing vocabulary do not rely on contextual cues, and although one may argue that this does not represent real-world vocabulary understanding and use, decontextualised language is an important characteristic of academic language (Rowe 2019).

\section{Bilingual vocabulary}

For the purpose of this study, bilingual children are defined as 'those who use two (or more) languages in their everyday life' (Armon-Lotem \& De Jong 2015:5), and this does not imply equal proficiency in the languages.

The assessment of vocabulary in both languages spoken by bilinguals is important because research has frequently shown that bilinguals have a smaller vocabulary in each of their languages than monolinguals speaking the same language (Burridge \& Stebbins 2016; Hoff et al. 2012; Thordardottir et al. 2006). However, because of the distributed nature of lexical knowledge, assessing bilinguals' vocabulary in only one language is likely to underestimate their proficiency (Gross, Busc \& Kaushanskaya 2014). As Bialystok et al. (2010:7) point out: 'the world is being constructed through two telescopes for bilingual children, and their two vocabularies provide the lenses'. It is important to capture this dual vocabulary knowledge. However, the challenge in assessing bilingual children is that some of their vocabulary overlaps across languages and some may be language-specific (Bedore et al. 2005). Thus, there may be concepts for which the bilingual knows a corresponding word only in language A and others only in language B (Gross et al. 2014). This is as a result of context-specific learning, resulting in exposure to certain lexical items in only one language. This is referred to as 'singlet vocabulary knowledge' (Gross et al. 2014:575). Other areas of vocabulary may be experienced in both languages and result in 'doublet vocabulary knowledge' (Gross et al. 2014:575). Bilingual children may have a larger proportion of singlets than doublets in their vocabularies (Mancilla-Martinez \& Vagh 2013; Sheng, Lu \& Kan 2011).

Consequently, Pearson, Fernandez and Oller (1993) developed a procedure known as conceptual scoring to capture bilingual vocabulary more accurately. This technique considers the total number of concepts for which a child knows a word, irrespective of the language in which the word is known. For example, an isiZulu-English child may know the word for 'shoe' in both English and isiZulu [isicathulo], but only know unogwaja [rabbit] in isiZulu and 'diamond' [idayimane] in English. This would result in a conceptual vocabulary score of 3 . Conceptual scoring has been found by several researchers to boost the measured vocabulary of bilingual children to the level of their monolingual peers and to be useful over a range of bilingual language experiences (Anaya, Peña \& Bedore 2018; Bedore et al. 2005; Marchman, Fernald \& Hurtado 2010). In addition, Marchman and Martinez-Sussman (2002) established that bilinguals' conceptual vocabulary score was positively correlated with their spontaneous language production.

However, conceptual scoring may be affected by test-specific factors (i.e. language and modality) and child-specific factors (i.e. acquisition history and socio-economic status) (Gross et al. 2014). The language for which the vocabulary test was designed (i.e. the child's first or second language) or the administration procedure may influence the conceptual score. Thus, translated tests assessing the same vocabulary in both languages may yield different results from tests where the vocabulary in the two language tests is different and based on the types of words to which the bilingual child may be exposed in each of his or her languages. In addition, if the administration of the test allows responses in either language, conceptual scores may be different from those obtained when only single-language responses are required. With respect to modality, conceptual scores may vary depending on whether receptive or expressive vocabulary is considered. Children may understand many more words than they can express, and thus the receptive conceptual score is likely to be higher than the expressive score. Therefore, it is important to assess both receptive and expressive vocabularies.

Bilingualism develops in different ways and a distinction is often made between simultaneous acquisition, when both languages are learnt from infancy, and sequential acquisition, 
when exposure to a second language occurs after infancy, usually at the start of preschool or first grade (Kohnert 2010). In either case, the duration and quality of exposure to each of the languages will contribute to proficiency and possibly also to the conceptual vocabulary.

\section{IsiZulu and Afrikaans}

Given the above factors affecting conceptual scoring, this study explored the receptive, expressive and conceptual vocabulary of Foundation Phase isiZulu-English and Afrikaans-English bilinguals, who, because of acquiring two different home languages, have different bilingual experiences and may demonstrate different patterns of vocabulary knowledge. isiZulu-English bilinguals were chosen on the basis that isiZulu is the most widely spoken language in South Africa and in Gauteng, where this study took place (Statistics South Africa 2016). In addition, children who are exposed to isiZulu in the home and community will typically start acquiring English when they enter preschool or first grade, thus being characterised as sequential bilinguals. Furthermore, there are interesting variations in the isiZulu spoken in urban Gauteng as opposed to the standard variety spoken in KwaZulu-Natal (Finlayson \& Slabbert 2004). This may affect the vocabulary of the tests as well as responses from the participants.

Afrikaans-English bilinguals may demonstrate different vocabulary acquisition patterns, with earlier and perhaps even simultaneous acquisition of Afrikaans and English in the home environment. In addition, a fairly standard variety of Afrikaans is spoken in Gauteng. Afrikaans was chosen as the other primary home language because although many Afrikaans children attend English schools, the acquisition of Afrikaans is generally well supported in language-rich home environments and exposure to Afrikaans teaching in the school context, potentially resulting in more balanced bilingualism (Coetzee-Van Rooy 2013).

\section{Educational context in South Africa}

Within the South African educational context, it is important to draw attention to the functioning of bilingual children, because despite the noble ideal of providing additive bilingual education, the reality is that South African children are being educated in English, either from the first grade or from Grade 4, with additional languages taught to varying extents. The participants in this study were all taught in English, their second language, and assessing their vocabulary in both English and isiZulu or Afrikaans would potentially answer the question as to whether the vocabulary of the home language is affected when instruction is done in English.

\section{Research aims}

The main aim of this study was to assess the receptive, expressive and conceptual vocabulary of isiZulu-English and Afrikaans-English bilingual children.
The objectives were to compare:

- the English and isiZulu or Afrikaans vocabulary scores within each of the bilingual groups to determine how the two languages compare with each other and whether education in English affects the home language vocabulary

- the vocabulary scores in each language with the conceptual scores within the bilingual groups to determine the best method of vocabulary assessment in bilingual children

- the receptive and expressive vocabulary scores in each language of the bilingual groups to determine how these modalities are affected by bilingualism

- the English vocabulary scores obtained by the bilingual groups with those of their monolingual peers to determine how the vocabularies of bilingual and monolingual children differ

- the conceptual vocabulary scores of the bilingual groups with the English vocabulary scores of the monolingual groups to determine whether conceptual scoring results in comparable vocabulary size across these two groups.

\section{Research methods and design}

The design of the study was quantitative, descriptive, cross-sectional and comparative in nature. Numerical data comprising the vocabulary scores obtained by the participants in both English and their home languages (isiZulu or Afrikaans) were analysed using statistical procedures (Schiavetti \& Metz 2006). The study was descriptive in that no deliberate experimentation or manipulation of variables occurred, and cross-sectional in that the data were collected at a single point in time (Hegde 2004). The study also included between- and within-group comparative components in that the vocabulary scores of the monolingual and bilingual participants were compared with each other and the scores of the bilingual learners were compared across their languages.

\section{Setting}

The study was conducted at two primary schools in Johannesburg, Gauteng province, where the language of teaching and learning is English from Grade 1. The schools were purposefully selected to ensure that there were sufficient numbers of monolingual English speakers as well as bilingual IsiZulu-English (site 1) and bilingual Afrikaans-English (site 2) learners. Both schools were former model C schools in the northern suburbs of Johannesburg. Learners attending the site 1 school are from the surrounding suburbs where their parents either live or work. The socio-economic status of the learners is varied. The majority of teachers at the school are first language English speakers. A variety of home languages were reported for the learners at the school. These included, but were not limited to, isiZulu, English, Sesotho, Sepedi, SiSwati, Xitsonga, Setswana, isiXhosa, French and Portuguese. Thus, in any given classroom, there is significant linguistic diversity and support for learning in the home language may be limited. Learners at site 2 were mostly from 
middle- and high-income families. Similar to the situation in site 1 school, the majority of teachers at this school were first language English speakers, but the number of first languages reported for the learners was less diverse and included only Afrikaans, English, isiZulu, isiXhosa and Portuguese.

\section{Study population and sampling strategy Sampling strategy}

A non-probability, purposive sampling strategy was employed by approaching the specific schools and inviting their participation.

\section{Criteria for selection of participants}

Participants were required to be healthy with no obvious cognitive, physical, hearing or visual impairments that might impact language development. At site 1, 8-year-old learners in Grade 2 were selected to ensure that they had sufficient exposure to English in a school environment at the time of assessment. At site 2, 7-year-old children in Grade 1 were selected, as their home and preschool exposure to both English and Afrikaans was considered to be sufficient to cope with the assessment. The bilingual learners were required to have IsiZulu (site 1) and Afrikaans (site 2) as their primary home languages, respectively. Confirmation of isiZulu or Afrikaans as a first language and English as a second language was established through the parent consent forms and school records. Children from either gender were eligible to participate in the study. Two monolingual English groups were included to serve as a comparison with the bilingual groups at each school. These participants were selected according to the same criteria (no obvious disabilities and ages 8 or 7 ) as the respective bilingual groups, but were required to speak only English at home.

\section{Description of participants}

Table 1 summarises the composition of the samples.

As shown in Table 1, the monolingual and bilingual groups at each site were matched for age and there was an equal distribution of male and female children at both sites

TABLE 1: Description of participant groups.

\begin{tabular}{lcccc}
\hline Group & $\begin{array}{c}\text { Number of } \\
\text { learners }\end{array}$ & Mean age & Males & Females \\
\hline $\begin{array}{l}\text { Monolingual English } \\
\text { learners } \\
\text { (site 1) }\end{array}$ & 30 & 8.4 & 15 & 15 \\
$\begin{array}{l}\text { Monolingual English } \\
\text { learners } \\
\text { (site 2) }\end{array}$ & 30 & 7.4 & 14 & 16 \\
$\begin{array}{l}\text { Bilingual isiZulu-English } \\
\text { learners } \\
\text { (site1) }\end{array}$ & 30 & 8.5 & 14 & 16 \\
$\begin{array}{l}\text { Bilingual Afrikaans-English } \\
\text { learners } \\
\text { (site2) }\end{array}$ & 30 & 7.4 & 16 & 14 \\
\hline \begin{tabular}{l} 
Total \\
\hline
\end{tabular} & $\mathbf{1 2 0}$ & - & 59 & $\mathbf{6 1}$ \\
\hline
\end{tabular}

31 female and 29 male children in site 1 and 30 female and 30 male children in site 2 .

\section{Data collection}

The instruments used to assess the vocabulary of the participants in this study were:

- the Receptive One-Word Picture Vocabulary Test 4 (ROWPVT-4) (Martin \& Brownell 2011a)

- the Expressive One-Word Picture Vocabulary Test 4 (EOWPVT-4) (Martin \& Brownell 2011b)

- adapted isiZulu and Afrikaans receptive and expressive one-word picture vocabulary tests based on the ROWPVT-4 and EOWPVT-4, respectively.

These instruments were selected based on previous research into vocabulary in bilingual individuals showing sensitivity to subtle vocabulary differences (Allman 2005; Pearson et al. 1993). The ROWPVT-4 and EOWPVT-4 are considered to be reliable and consistent measures of vocabulary (Allman 2005). These vocabulary tests were also chosen above others as they have been translated into several languages, suggesting their suitability for adaptation into other languages. For example, Allman (2005) used the English and Spanish standardised versions of the EOWPVT to compare English and Spanish monolinguals and bilinguals. Dionysios et al. (2010) adapted both tests into Greek for the school-aged Greek population and found the tests to be sufficiently sensitive. Chiang and Rvachew (2007) used the English EOWPVT and an adapted French version to assess vocabulary of bilingual children in Canada. The ROWPVT and EOWPVT have not been used extensively in research in South Africa and so the validity of their use in this context can be commented on in the present study.

The ROWPVT-4 assesses an individual's ability to identify objects, actions and concepts based on a spoken word when given a choice of four illustrations (Martin \& Brownell 2011a), for example, show me aquatic. This task targets the understanding of words and is referred to as receptive vocabulary. Cueing, prompting and picture clarifications are not allowed (Martin \& Brownell 2011a). Some adjustments were made to test items in the ROWPVT- 4 in the present study to make them more culturally appropriate to the South African context. Linguistically equivalent words were used to ensure that the integrity of the test was not compromised. Table 2 shows which English words were changed to better suit the South African context.

The EOWPVT-4 assesses the ability to name objects, actions and concepts when presented with illustrations and is referred to as expressive vocabulary (Martin \& Brownell 2011b), for example, what is this? or what is he doing? Only prompts specified in the scoring manual for each item were used to elicit a response from the participants, for example, what is this? for a singular object and what is one word for all of these for a group of objects such as fruit. Additional cueing 
TABLE 2: English Receptive One-Word Picture Vocabulary Test 4 items adapted for the South African population.

\begin{tabular}{lllll}
\hline Item number & $\begin{array}{l}\text { ROWPVT prompt } \\
\text { 'Show me ...' }\end{array}$ & $\begin{array}{l}\text { Adjusted prompt } \\
\text { 'Show me ...' }\end{array}$ & Nature of change & Reason \\
\hline 21 & Bear & Frog & Response & Bears are not native to South Africa and so may be a source of bias. Frogs are common in South Africa. \\
26 & Cookie & Biscuit & Prompt & 'Cookie' is not commonly used in South Africa. 'Biscuit' is more accurate. \\
45 & Baseball & Tennis & Response & Baseball is not a sport that is prevalent in South Africa. Tennis is played at most schools in South Africa. \\
100 & Burners & Plates & Prompt & Burners are more commonly referred to as plates in South Africa. \\
\hline
\end{tabular}

ROWPVT, The Receptive One-Word Picture Vocabulary Test.

was used if the participant was not attending to the correct part of an illustration, for example, labelling 'sky' for the illustration of 'cloud' as a result of inattention to the arrow pointing to the cloud. Additional cueing was not used if an item was labelled incorrectly, for example, labelling a cloud as 'rain'. Additional cueing was given if the participant responded with a sentence or a phrase, where a single word was required. Misarticulations were not scored as incorrect. Where applicable, a variety of responses were acceptable and listed on the response form, for example, rug/carpet/mat. One adjustment was made to the list of acceptable responses, that is, mielie for 'corn' to make it more culturally appropriate to the South African context.

In both the tests, repetition of the target word is allowed and neutral feedback is given after each response. The participants were not given the correct answer for incorrect responses in order to avoid influencing future performance, specifically by the bilingual participants. Both the ROWPVT- 4 and the EOWPVT-4 are individually administered tests and were developed to be used on ages 2-80+ years (Martin \& Brownell 2011a, 2011b). Thus, these tests were considered suitable to assess the expressive and receptive vocabulary of 7- and 8-year-olds for the purpose of this study. Both tests have basal and ceilings that are guided by age and the number of correct or incorrect responses. For this study, basals and ceilings were not used as the raw data collected in this study would not be compared with the normative data provided in the test manuals. Participants completed all items up to number 110. This self-imposed ceiling was chosen based on the average raw scores achieved by 7-8-year-olds according to the ROWPVT-4 and EOWPVT-4 formal data.

\section{Adapted isizulu and Afrikaans vocabulary tests}

The English ROWPVT-4 and EOWPVT-4 were adapted into isiZulu and Afrikaans. The method of testing one language at a time using two separate tests, that is, an English test and an isiZulu/Afrikaans test, was supported by Anaya et al. (2018), who found that this method resulted in higher scores and a more accurate conceptual vocabulary score. This was in contrast to using one test and prompting for responses in either one or both languages at the same time. Anaya et al. (2018) found that scores are negatively affected by the demands of code-switching between the two languages. Despite the limitations of translated tests, the English tests were translated into isiZulu and Afrikaans in this study, mainly because of a paucity of research on the vocabulary to which isiZulu and Afrikaans children are exposed, which would allow for different tests to be constructed in these languages. In addition, the vocabulary assessed in the English ROWPVT-4 and EOWPVT-4 was considered to be basic and fairly universal in terms of the concepts assessed.

Nonetheless, adaptation and administration of the tests were carried out with the aid of isiZulu and AfrikaansEnglish bilingual translators. The English words were given to one translator to translate independently into isiZulu or Afrikaans while another translator was asked to back-translate the isiZulu or Afrikaans words into English to assess the validity of the translations. This process was repeated twice and acceptable words and variations were deliberated on by all parties. While translating and backtranslating may provide well-translated materials, cultural and linguistic equivalence must also be considered (Peña 2007). Many of the English words in the ROWPVT-4 and EOWPVT-4 did not have direct isiZulu translations and so were not included in the isiZulu assessments. This resulted in the isiZulu ROWPVT- 4 and EOWPVT-4 consisting of 88 and 102 items, respectively. Care was taken to ensure that the words were linguistically equivalent, for example, 'slumber' was not adapted to 'sleep' in the isiZulu version. In contrast, it was possible to translate all the test items into Afrikaans, resulting in the Afrikaans versions consisting of 110 items.

\section{Procedure for data collection}

Each participant was tested on the school grounds at minimal disruption to the academic schedule. The adapted isiZulu/Afrikaans tests were administered by trained first language isiZulu/Afrikaans speakers who were familiar with children, vocabulary testing and the research process. The testing was supervised by the researchers. Scoring and prompting were the same as for the English EOWPVT-4 and ROWPVT-4. The only notable prompting differences were for the expressive testing, where children required inconsistent reminders to provide the isiZulu/Afrikaans name, rather than a slang word where a word is adapted from another language, for example, itrain for 'train' where isitimela is the correct word in isiZulu. The AfrikaansEnglish bilinguals tended to provide the English word and had to be prompted for the Afrikaans word.

Testing lasted approximately 30 minutes for both the expressive and receptive portions of the assessments in each language. Monolingual learners were only assessed in English. The isiZulu/Afrikaans bilinguals completed half the receptive and expressive vocabulary test in English first, and 
then half in isiZulu/Afrikaans and vice versa, so as to counterbalance the effects of familiarity.

\section{Reliability and validity}

External validity in this study was addressed by having an adequate sample size of 30 monolingual and 30 bilingual learners at each site. A small sample of the population at each site $(n=10)$ was scored by both an examiner and a researcher to establish inter-rater reliability. There was $100 \%$ agreement in scoring in these instances. A small sample size $(n=10)$ was also tested twice with $100 \%$ agreement between the two tests, resulting in a Pearson's correlation coefficient of 1 , confirming test-retest reliability. All the isiZulu and Afrikaans scores were reviewed by a second L1 isiZulu/Afrikaans speaker and there was $100 \%$ agreement between scores on all 60 assessments at each site. Raw data entries were checked independently to ensure accurate data capturing.

\section{Data analysis}

Participants' scores for each item on each test were entered onto spreadsheets, containing an assigned number for each participant, gender and first language. The raw scores for each monolingual and bilingual group on each test were used to calculate a standard mean, standard deviation and range of scores. It is important to note that this is a standard mean based on peer scores and not on the standard norms as published with the EOWPVT-4 and ROWPVT-4 manuals. Mean scores were converted to percentages for ease of comparison. Conceptual receptive and expressive vocabulary scores were calculated for each participant using the method described in Table 3.

Within the group, comparisons were performed using paired sample $t$-tests to compare the receptive and expressive isiZulu/Afrikaans and English scores in the bilingual groups and the English receptive and expressive scores in the monolingual groups. The Pearson correlation coefficient was performed to determine correlations between receptive and expressive measures in each group of monolingual and bilingual participants at each site.

TABLE 3: Example of the method used to calculate conceptual scores for bilingual participants.

\begin{tabular}{lccc}
\hline Vocabulary item & English & Afrikaans/isiZulu & Conceptual score \\
\hline Shoe & $\checkmark$ & X & $\checkmark$ \\
Saxophone & X & $\checkmark$ & $\checkmark$ \\
Sailboat & X & $\checkmark$ & $\checkmark$ \\
People & X & $\checkmark$ & $\checkmark$ \\
Nose & $\checkmark$ & X & $\checkmark$ \\
Pear & $\checkmark$ & $\checkmark$ & $\checkmark$ \\
Fingerprint & X & X & X \\
Onion & X & $\checkmark$ & $\checkmark$ \\
Car & X & X & X \\
Thumb & $\checkmark$ & $\checkmark$ & $\checkmark$ \\
\hline Total score/10 & 4 & 6 & 8 \\
\hline
\end{tabular}

Note: Statistical analysis of the data was performed by a qualified statistician using the SPSS package.

$X$, incorrect; $\checkmark$, correct.
Independent sample $t$-tests were used to compare the monolingual and bilingual groups at each site on the English ROWPVT-4 and EOWPVT-4 scores as well as the monolingual English scores and the bilingual conceptual scores at each site.

All of the between- and within-group statistical comparisons were deemed significant if the probability $(p)$ of rejecting the null hypothesis was $<5 \%(p<0.05)$.

\section{Ethical consideration}

Approval and ethical clearance to conduct the study were obtained from the Human Research Ethics Committee (Non-medical) of the University of the Witwatersrand (clearance number: H14/06/29 [site 1] and H16/07/39 [site 2]). The proposed study was presented to and approved by the Gauteng Department of Education. The principals at the identified schools gave permission for participation and the respective teachers at each school were given information regarding the study and were asked to assist with the identification of suitable participants. An information letter and consent form were sent home with selected learners who met the criteria for participating in the study. Learners participated only if a parent or guardian had given written consent. The researchers explained the study in a childfriendly manner to the learners who had returned completed consent forms and if the learners gave assent, they were included in the study. Participation was entirely voluntary. Participants' anonymity was protected by assigning numbers and not using their names in the data capturing.

\section{Results}

The means, standard deviations and range of scores obtained by each participant group at each site on the receptive and expressive vocabulary measures in each language, as well as the conceptual vocabulary scores obtained by the bilingual groups, are captured in Tables 4 and 5.

The data in Tables 4 and 5 show that the mean percentage scores are above $74 \%$ in all groups with the exception of the expressive vocabulary scores in the home languages of the bilingual groups. The relatively high scores confirm that the participants in this study were able to identify and name at least three-quarters of the vocabulary items in the tests and have reasonably well-developed vocabularies. The results are further analysed to highlight within- and between-group differences.

\section{Within-group comparisons}

\section{Comparisons between English and home language scores in bilingual groups}

Within the isiZulu-English bilingual group, the English scores were significantly higher than the isiZulu scores on both the receptive $(t=6.39 ; p=0.0001 ; d f=29)$ and expressive $(t=19.45 ; p=0.000 ; d f=29)$ vocabulary measures. This group obtained a mean score of $83.3 \%$ on the English and 
TABLE 4: Mean scores, standard deviations, minimum, maximum and range of scores for monolingual and bilingual groups at site 1 on the receptive and expressive vocabulary measures in English and isizulu and conceptual vocabulary scores for the bilingual group.

\begin{tabular}{|c|c|c|c|c|c|c|}
\hline \multirow[t]{2}{*}{ Participant group } & \multicolumn{2}{|c|}{ Mean raw score (mean percentage) } & \multirow[t]{2}{*}{ Standard deviation } & \multirow[t]{2}{*}{ Minimum score } & \multirow[t]{2}{*}{ Maximum score } & \multirow[t]{2}{*}{ Range } \\
\hline & $n$ & $\%$ & & & & \\
\hline Monolingual group receptive vocabulary score & $100 / 110$ & 90.9 & 4.05 & 90 & 108 & 18 \\
\hline Monolingual group expressive vocabulary score & $98.1 / 110$ & 89.2 & 4.58 & 90 & 107 & 17 \\
\hline Bilingual group English receptive vocabulary score & $91.6 / 110$ & 83.3 & 5.33 & 82 & 102 & 20 \\
\hline Bilingual group English expressive vocabulary score & $86.1 / 110$ & 78.3 & 8.95 & 58 & 97 & 39 \\
\hline Bilingual group isizulu receptive vocabulary score & $71.5 / 88$ & 81.3 & 6.69 & 59 & 80 & 21 \\
\hline Bilingual group conceptual receptive vocabulary score & $94.5 / 110$ & 85.9 & 5.12 & 82 & 102 & 20 \\
\hline Bilingual group conceptual expressive vocabulary score & $87.2 / 110$ & 79.3 & 7.87 & 65 & 99 & 34 \\
\hline
\end{tabular}

TABLE 5: Mean scores, standard deviations, minimum, maximum and range of scores for monolingual and bilingual groups at site 2 on the receptive and expressive vocabulary measures in English and Afrikaans and conceptual vocabulary scores for the bilingual group.

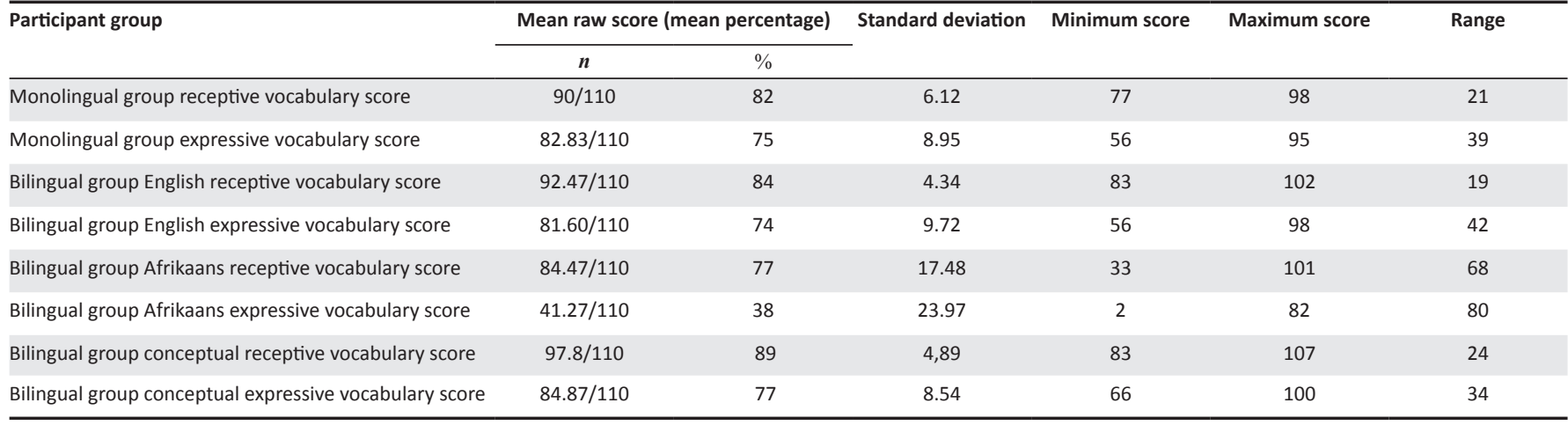

$81.3 \%$ on the isiZulu receptive vocabulary test, and $78.3 \%$ on the English and $39.2 \%$ on the isiZulu expressive vocabulary measures.

Similarly, within the Afrikaans-English bilingual group, the English scores were significantly higher than the Afrikaans scores on both the receptive $(t=3.12 ; p=0.0081 ; d f=29)$ and expressive $(t=9.63 ; p=0.000 ; d f=29)$ vocabulary measures. This group obtained $84 \%$ on the English and $77 \%$ on the Afrikaans receptive vocabulary test and $74 \%$ on the English and $38 \%$ on the Afrikaans expressive vocabulary measures.

\section{Comparison between scores in each language and conceptual scores in bilingual groups}

Within the IsiZulu-English bilingual group, the mean conceptual receptive vocabulary score was $85.9 \%$, which was significantly higher than the English (83.3\%) $(t=4.90$; $p=0.001 ; d f=29)$ and IsiZulu (81.3\%) $(t=24.07 ; p=0.000$; $d f=29)$ receptive vocabulary scores. The conceptual expressive vocabulary score (79.3\%) was significantly higher than the isiZulu expressive vocabulary score (39.2\%) $(t=18.61 ; p=0.000 ; d f=29)$ as well as the English expressive vocabulary score $(t=2.39 ; p=0.0471 ; d f=29)$, although this difference was only just significant at the $5 \%$ level.

Similarly, the mean scores increased significantly for both receptive (89\%) and expressive (77\%) measures using conceptual scoring in the Afrikaans-English bilingual group. The receptive conceptual vocabulary score was significantly higher than the receptive vocabulary score in both English $(t=9.86 ; p=0.00 ; d f=29)$ and Afrikaans $(t=5.61 ; p=0.00$; $d f=29)$. The expressive conceptual score was also significantly higher than both the English $(t=5.23 ; p=0.00 ; d f=29)$ and the Afrikaans expressive score $(t=11.31 ; p=0.00 ; d f=29)$.

\section{Receptive-expressive vocabulary comparisons}

As would be expected in typically developing children, both the monolingual and bilingual groups at the two sites obtained higher mean scores on the receptive vocabulary measures than on the expressive vocabulary measures, but the differences were not always statistically significant. For example, a paired sample $t$-test revealed that the difference between the receptive and expressive vocabulary scores was not significant $(t=2.33$; $p=5.4185$; $d f=29$ ) in the monolingual group at site 1 and the receptive and expressive scores were also not significantly correlated $(r=0.33 ; p=7.3410)$ in this group. In contrast, the difference between the receptive and expressive scores was significant $(t=7.08 ; p=0.00 ; d f=29)$ in the monolingual group at site 2 , indicating a difference between the participants' understanding and use of vocabulary in this younger group. The receptive and expressive vocabulary scores within this monolingual group were also significantly correlated $(r=0.71 ; p=0.00)$.

A striking finding in both bilingual groups was the low scores obtained on the expressive vocabulary tests in their home languages. The bilingual group at site 1 obtained a mean score of $39.2 \%$ on the isiZulu expressive measure, and similarly the bilingual group at site 2 obtained a mean score of $38 \%$ on the Afrikaans expressive measure. There was also much more individual variation in scores on the expressive vocabulary measures in English, home languages and 
conceptual scores, as seen in the larger standard deviations and range of scores recorded in Tables 4 and 5 for both the monolingual and bilingual groups.

Within the bilingual isiZulu-English group, a paired sample $t$-test revealed a significant difference between the receptive and expressive vocabulary scores in both English $(t=7.05$; $p=0.00 ; d f=29)$ and isiZulu $(t=6.72 ; p=0.00 ; d f=29)$, showing a significant difference in understanding and use of vocabulary in both languages. In contrast to the monolingual group, the receptive and expressive scores were significantly correlated in both English $(r=0.5 ; p=0.0502)$ and isiZulu $(r=0.58 ; p=0.082)$ in this group. Similarly, there were significant differences between the receptive and expressive scores in both English $(t=8.08 ; p=0.00 ; d f=29)$ and Afrikaans $(t=10.67 ; p=0.00 ; d f=29)$ in the bilingual Afrikaans-English group at site 2 . In this group, the receptive and expressive scores were also significantly correlated in English $(r=0.65$; $p=0.00 \%)$ and Afrikaans $(r=0.43 ; p=0.00 \%)$.

\section{Between-group comparisons}

\section{Monolingual-Bilingual comparisons on English tests}

At site 1, the monolingual group obtained significantly higher scores than the isiZulu-English bilingual group on both the English receptive vocabulary $(t=7.015 ; p=0.00$; $d f=58)$ and expressive vocabulary measures $(t=6.718$; $p=0.00 ; d f=58)$.

In contrast, the differences between the monolingual and Afrikaans-English bilinguals at site 2 were not statistically significant on either the receptive $(t=2.12 ; p=0.769 ; d f=58)$ or expressive vocabulary $(t=1.05 ; p=5.97 ; d f=58)$ measures.

\section{Monolingual-Bilingual comparisons on conceptual scores}

When the conceptual scores obtained by the bilingual isiZulu-English group are compared with the English scores of the monolingual group at site 1 , there is a significant difference in favour of the monolingual group on both the receptive $(t=4.657 ; p=0.0132 ; d f=58)$ and expressive $(t=7.991 ; p=0.000 ; d f=58)$ vocabulary measures. Thus, despite the bilingual group's scores improving when conceptual scoring is applied, they still obtain significantly lower scores than the monolingual group. The bilingual group obtained a mean conceptual receptive vocabulary score of $85.9 \%$ and a mean conceptual expressive vocabulary score of $79.3 \%$, while their monolingual peers obtained significantly higher scores of $90.9 \%$ and $89.2 \%$ on the receptive and expressive English vocabulary measures, respectively.

In contrast, when their conceptual scores are used as the basis for comparison, the bilingual Afrikaans-English bilinguals at site 2 obtained significantly higher scores than the monolingual group on the receptive $(t=5.64 ; p=0.00 ; d f=58)$ vocabulary measure but not on the expressive vocabulary measure $(t=1.37 ; p=0.3514 ; d f=58)$. The bilingual group obtained a conceptual receptive vocabulary score of $89 \%$ and a conceptual expressive vocabulary score of $77 \%$, while their monolingual peers obtained $82 \%$ and $75 \%$ on the receptive and expressive English tests, respectively.

\section{Discussion}

In answer to the research question, 'how do the vocabularies in the two languages of bilinguals compare with each other?', the results of this research suggest that both groups of bilinguals have significantly larger receptive and expressive vocabularies in English than in their home languages, suggesting that for lexical functioning, the bilinguals are more proficient in English. This, together with the fact that both bilingual groups obtained much lower scores on the expressive vocabulary tests than in their home languages, indicates that their dominance in English is more evident in expressive language. This may be interpreted to be the result of being educated in English, with the implication that the development of vocabulary in the home languages of bilinguals may be negatively affected by instruction in English.

However, the conceptual vocabulary scores are significantly higher than scores on single languages across receptive and expressive modalities in both bilingual groups. These results correlate with previous studies that employed the same method of assessment and conceptual scoring (Kan \& Kohnert 2005; Pearson et al. 1993). When using conceptual scoring, bilinguals obtained much higher scores than when single language test results were used, emphasising the importance of this method of testing and scoring for bilingual children. It also indicates that the bilingual children in this study had more 'singlets' in their vocabulary than 'doublets' (Gross et al. 2014:575), having been exposed to different vocabulary in each of their languages. Conceptual vocabulary thus provides a more accurate picture of the lexical knowledge of bilingual children and proves to be the best method of assessing their vocabulary. This confirms that bilingual children are able to view the world through two lenses and one cannot assume that their vocabulary is negatively affected by being educated in English.

The question arises as to how differences in vocabulary knowledge across their two languages affect bilinguals who need to function in an educational environment requiring the use of one language only (in this case English), and, in particular, if they are competing with monolingual peers. This question may be answered using the comparisons between the monolingual and bilingual groups, which confirm that the vocabularies of these two groups may differ depending on which measures are used and which bilinguals are being assessed. At site 1, the monolingual group obtained significantly higher scores than the isiZulu-English bilingual group on both the English receptive and expressive vocabulary measures, while the differences between the monolingual and bilingual Afrikaans-English bilinguals at site 2 were not statistically significant on either the receptive or expressive vocabulary measures. 
When the conceptual scores obtained by the bilingual isiZulu-English group are compared with the English scores of the monolingual group at site 1 , there is a significant difference in favour of the monolingual group on both the receptive and expressive vocabulary measures. Thus, despite the bilingual group's scores improving when conceptual scoring is applied, they still obtain significantly lower scores than the monolingual group.

In contrast, when their conceptual scores are used as the basis for comparison, the bilingual Afrikaans-English bilinguals at site 2 obtained significantly higher scores than the monolingual group on the receptive vocabulary measure but not on the expressive vocabulary measure.

The above findings suggest that the IsiZulu-English bilinguals need support in developing their English vocabulary if they are to compete with their monolingual peers. According to Cummins (2000), bilingual effects on cognition are neither positive nor negative, provided that the language of instruction is sufficiently developed to support learning. The results of this study suggest that this condition may be different for the two bilingual groups in that the isiZulu-English group obtains significantly lower scores than the monolingual group in English, even with conceptual scoring. If monolingual standards are used to assess them, they are at a disadvantage and would require support in the language of instruction to avoid negative effects on academic performance. In contrast, the Afrikaans-English bilinguals do not obtain significantly lower scores than their monolingual peers in English, and even obtain higher scores than the monolingual group when conceptual scores are used. Thus, they are not disadvantaged in the language of instruction.

A possible explanation for this difference between the two groups of bilinguals when their English and conceptual scores are compared to those of their monolingual peers is that they have different exposure trajectories. The isiZuluEnglish participants would most likely have been sequential bilinguals who were exposed to English later than the Afrikaans-English bilinguals, who were more likely to have been simultaneous bilinguals, exposed to both languages from an earlier age.

The researchers were concerned that the linguistic differences between the isiZulu and English tests would result in better scores in English. This was because isiZulu translation equivalents could not be found for some of the words in both the ROWVT-4 and EWOVT-4, and the children might not have known the standard isiZulu words, as a result of their exposure to the Gauteng variety. However, the fact that the Afrikaans-English bilinguals performed similarly to the isiZulu-English bilinguals in terms of significantly better scores in English than in the home language would suggest that these linguistic variations did not play a significant role.

As shown in Tables 4 and 5, both the monolingual and bilingual groups at site 1 obtained consistently higher scores than their younger peers at site 2 on all measures, with the exception of the English receptive and conceptual receptive vocabulary scores in the bilingual groups, where the differences were minimal. Although these differences were not tested for statistical significance, as the aim of the study was not to compare the scores of the two bilingual groups, it is clear that the age of the participants had an impact on their vocabulary scores. This was particularly apparent for the monolingual groups, who obtained $90.9 \%$ and $82 \%$ on the receptive vocabulary measure, and $89.2 \%$ and $75 \%$ on the expressive vocabulary measure at first (older group) and second (younger group) sites, respectively. These results suggest that the vocabulary measures employed in this study are generally sensitive to age differences and lend support to their validity. Incidentally, both the monolingual groups' scores were comparable to the age norms provided in the EOWPVT-4 and the ROWPVT-4 for 7- and 8-yearolds, suggesting that these tests are suitable for English monolingual children in South Africa.

Finally, in both bilingual groups and the younger monolingual group at site 2 , there are significant differences between receptive and expressive scores in both languages, and the receptive and expressive scores are positively correlated. These findings imply that a better understanding of words supports a better expressive lexicon.

\section{Conclusion}

The results of this study have confirmed the value of considering the rich dual language knowledge of bilingual children and the distribution of their lexical knowledge across their languages. It has also highlighted the need for educators to be aware of the vocabulary differences between monolingual and bilingual children and the need for continued support in the development of both languages in bilingual children.

\section{Acknowledgements}

The authors would like to thank the learners, teachers and parents of the participating schools.

\section{Competing interests}

The authors declare that they have no financial or personal relationships that may have inappropriately influenced them in writing this article.

\section{Authors' contributions}

H.L.J., A.v.Z. and T.O. contributed equally to this article.

\section{Funding information}

This research received no specific grant from any funding agency in the public, commercial or not-for-profit sectors.

\section{Data availability statement}

Data are available on request from the corresponding authors. 


\section{Disclaimer}

The views and opinions expressed in this article are those of the authors and do not necessarily reflect the official policy or position of any affiliated agency of the authors.

\section{References}

Allman, B., 2005, 'Vocabulary size and accuracy in monolingual and bilingual preschool children', in J. Cohen, K. McAlister, K. Rolstad \& J. MacSwan (eds.), ISB4: Proceedings of the 4th international smposium on bilingualism, pp. 58-77, Cascadilla Press, Somerville, MA.

Anaya, J.B., Peña, E.D. \& Bedore, L.M., 2018, 'Conceptual scoring and classification accuracy of vocabulary testing in dual language knowledge of bilingual children' Language, Speech \& Hearing Services in Schools 49(1), 85-97. https://doi. org/10.1044/2017_LSHSS-16-0081

Armon-Lotem, S. \& de Jong, J., 2015, 'Introduction', in S. Armon-Lotem, J. De Jong \& N. Meir (eds.), Assessing multilingual children: Disentangling bilingualism from language impairment, pp. 1-22, Multilingual Matters, Bristol.

Bedore, L.M., Peña, E.D., Garcia M. \& Cortez, C., 2005, 'Conceptual versus monolingual scoring: When does it make a difference?', Speech, Language \& Hearing Services in Schools 36(3), 188-200. https://doi.org/10.1044/0161-1461(2005/020)

Bialystok, E., Luk, G., Peets, K.F. \& Yang, F., 2010, 'Receptive vocabulary differences in monolingual and bilingual children', Journal of Bilingualism 13(4), 525-533. https://doi.org/10.1017/S1366728909990423

Burridge, K. \& Stebbins, T.N., 2016, For the love of language an introduction to linguistics, Cambridge University Press, Melbourne.

Chiang, P. \& Rvachew, S., 2007, 'English-French bilingual children's phonological awareness and vocabulary skills', Canadian Journal of Applied Linguistics 10(3) 293-308.

Coetzee-Van Rooy, S., 2013, 'Afrikaans in contact with English: Endangered language or case of exceptional bilingualism?', International Journal of the Sociology of Language 2013(224), 179-207. https://doi.org/10.1515/ijsl-2013-0060

Cummins, J., 2000, Language, power, and pedagogy: Bilingual children in the crossfire, Multilingual Matters, Clevedon, Buffalo, NY.

Dickinson, D.K. \& Porche, M.V., 2011, 'Relation between language experiences in preschool classrooms and children's kindergarten and fourth-grade language and reading abilities', Child Development 82, 870-886. https:// doi:10.1111/j.1467-8624.2011.01576.x

Dionysios, T., Bergadi, A., Gkrekou, X., Karagianni, E., Kntakou, F., Kentioglou, K. et al., 2010, 'The expressive and the receptive one word picture vocabulary test (EOWPVT \& ROWPVT): A combined pilot study in Greek school-aged children and data for expressive and receptive language for this population', Annals of General Psychiatry 9 (suppl. 1), S193. https://doi.org/10.1186/1744859X-9-S1-S193

Durgunoğlu, A.Y. \& Bigelow, M., 2017, 'Classroom-based L2 vocabulary learning and comprehension: Replications of Lesaux, Kieffer, Faller \& Kelley (2010)', Language Teaching 50(3), 384-394. https://doi.org/10.1017/S0261444816000239

Finlayson, R. \& Slabbert, S., 2004, 'What turns you on: An exploration of urban South African Xhosa and Zulu youth texts', in M.J. Muthwii \& A.N. Kioko (eds.), New language bearings in Africa: A fresh quest, pp. 69-76, Multilingual Matters, Bristol, UK.

Gross, M., Busc, M. \& Kaushanskaya., 2014, 'Conceptual scoring of receptive and expressive vocabulary measures in simultaneous and sequential bilingua children', American Journal of Speech Language Pathololgy 23(4), 574-586. https://doi.org/10.1044/2014_AJSLP-13-0026
Hegde, M.N., 2004, Clinical research in communicative disorders: Principles and strategies, 3rd edn., Pro-Ed, Austin, TX.

Hoff, E., 2006, 'How social contexts support and shape language development' Developmental Review 26(1), 55-88. https://doi.org/10.1016/j.dr.2005.11.002

Hoff, E., Core, C., Place, S., Rumiche, R., Senor, M. \& Parra, M., 2012, 'Dual language exposure and early bilingual development', Journal of Child Language 39(1), 1-27. https://doi.org/10.1017/S0305000910000759

Howie, S., Combrinck, C., Roux, K., Tshele, M., Mokoena, G. \& Palane, N.M., 2017 Progress in international reading literacy study 2016: South African children's reading literacy achievement, University of Pretoria, Faculty of Education, Centre for Evaluation and Assessment, Pretoria.

Kan, P.F. \& Khonert, K., 2005, 'Preschoolers learning Hmong and English: Lexicalsemantic skills in L1 and L2', Journal of Speech, Language and Hearing research $48,372-383$.

Kim, Y. \& Pallante, D., 2012, 'Predictors of reading skills for kindergartners and first grade students in Spanish: A longitudinal study', Reading and Writing 25, 1-22. https://doi.org/10.1007/s11145-010-9244-0

Kohnert, K., 2010, 'Bilingual children with primary language impairment: Issues, evidence and implications for clinical actions', Journal of Communication Disorders 43(6), 456-473. https://doi.org/10.1016/j.jcomdis.2010.02.002

Mancilla-Martinez, J. \& Vagh, S.B., 2013, 'Growth in toddlers' Spanish, English, and conceptual vocabulary knowledge', Early Childhood Research Quarterly 28(3), 555-567. https://doi.org/10.1016/j.ecresq.2013.03.004

Marchman, V.A. \& Martinez-Sussmann, C., 2002, 'Concurrent validity of caregiver/ parent report measures of language for children who are learning both English and Spanish', Journal of Speech, Language, and Hearing Research 45(5), 983-997. https://doi.org/10.1044/1092-4388(2002/080)

Marchman, V.A., Fernald, A. \& Hurtado, N., 2010, 'How vocabulary size in two languages relates to efficiency in spoken word recognition by young Spanish-
English bilinguals', Journal of Child Language 37(4), 817-840. https://doi. English bilinguals', Journal of Child
org/10.1017/S0305000909990055

Martin, N. \& Brownell, M.A., 2011a, Expressive one-word picture vocabulary test, 4th edn., Academic Therapy Publications, Novado, CA.

Martin, N. \& Brownell, M.A., 2011b, Receptive one-word picture vocabulary test, 4th edn., Academic Therapy Publications, Novado, CA.

Pearson, B.Z., Fernandez, S.C. \& Oller, D.K., 1993, 'Lexical development in bilingual infants and toddlers - Comparison to monolingual norms', Language Learning 43(1), 93-120. https://doi.org/10.1111/j.1467-1770.1993.tb00174.x

Peña, E.D., 2007, 'Lost in translation: Methodological considerations in crosscultural research', Child Development 78(4), 1255-1264. https://doi. org/10.1111/j.1467-8624.2007.01064.x

Rowe, M.L., 2019, 'Learning more than language through language in early childhood', in V. Grover, P. Uccelli, M.L. Rowe \& E. Lieven (eds.), Learning through language towards an educationally informed theory of language learning, pp. 40-51, towards an educationally
Cambridge University Press.

Schiavetti, N. \& Metz, D.E., 2006, Evaluating research in communication disorders, Pearson Education, New Jersey.

Seifert, D., 2016, Top 5 reasons why vocabulary matters, Infercabulary, viewed 04 Apri 2020, from https://infercabulary.com/top-5-reasons-why-vocabulary-matters/

Sheng, L., Lu. Y. \& Kan, P.F., 2011, 'Lexical development in Mandarin-English bilingual children', Bilingualism-Language and Cognition 14(4), 579-587. https://doi. org/10.1017/s1366728910000647

Statistics South Africa, 2016, Provincial profile: Gauteng Community Survey 2016 Report number 03-01-09, viewed 05 April 2020, from statssa.gov.za/wp-content/ Report number 03-01-09, viewed
uploads/2018/07/Gauteng.pdf.

Thordardottir, E., Rothenberg, A., Rivard, M. \& Naves, R., 2006, 'Bilingual assessment: Can overall proficiency be estimated from separate measurement of two languages?', Journal of Multilingual Communication Disorders 4(1), 1-21. https:// doi.org/10.1080/14769670500215647 